\title{
Can radiographic measurements of degenerative lumbar scoliosis predict clinical symptoms?
}

\section{Avraam Ploumis*, Hong Liu, Amir Mehbod and Ensor Transfeldt}

Address: Twin Cities Spine Center, Minneapolis, MN, USA

* Corresponding author

from $5^{\text {th }}$ International Conference on Conservative Management of Spinal Deformities

Athens, Greece. 3-5 April 2008

Published: 15 January 2009

Scoliosis 2009, 4(Suppl I):O54 doi:I0.II86/I748-7|6|-4-SI-O54

This abstract is available from: http://www.scoliosisjournal.com/content/4/SI/O54

(C) 2009 Ploumis et al; licensee BioMed Central Ltd.

\section{Background}

Sagittal alignment is more critical than coronal curve magnitude in clinical presentation of patients with adult deformity.

\section{Purpose}

To evaluate the radiographic parameters of patients with degenerative adult scoliosis and to correlate them with functional scores.

\section{Methods}

Radiographic analysis of 56 patients with degenerative lumbar scoliosis was performed in anteroposterior and lateral 36-inch standing radiographs. Measurements included curve type, curve location, curve magnitude, coronal balance, sagittal balance, and rotatory olisthesis. Clinical functional results were measured with Oswestry disability index and SF-36 form. Correlation between clinical and radiographic results was calculated.

\section{Results}

Patients with positive sagittal imbalance and rotatory olisthesis >grade I demonstrated poorer functional results. Patients with coronal imbalance less than $4 \mathrm{~cm}$ did not affect their functional outcomes. Patients with lumbar major curves experienced worse symptomatology than those with thoracolumbar major curves.

\section{Conclusion}

Positive sagittal imbalance and moderate to severe rotatory olisthesis in the lumbar curves are important radiographic parameters which may correlate to degree of symptomatology in adult patients with degenerative scoliosis. Treatment of these patients should focus on improvement of aforementioned parameters.

\section{References}

I. Glassman SD, Bridwell K, Dimar JR, et al:: The impact of positive sagittal balance in adult spinal deformity. Spine 2005, 30:2024-9.

2. Schwab F, Dubey A, Gamez L, et al.: Adult scoliosis: prevalence, SF-36, and nutritional parameters in an elderly volunteer population. Spine 2005, 30: 1082-5.

3. Schwab FJ, Smith VA, Biserni M, et al.: Adult scoliosis: a quantitative radiographic and clinical analysis. Spine 2002, 27:387-92. 